\title{
Population-Based Teacher-Rated Assessment of Anxiety Among Canadian Kindergarten Children
}

\author{
Magdalena Janus $^{1}$ (D) Julia Ryan ${ }^{2} \cdot$ Molly Pottruff $^{1} \cdot$ Caroline Reid-Westoby $^{1} \cdot$ Marni Brownell $^{3} \cdot$ Teresa Bennett $^{1}$. \\ Catherine S. Birken ${ }^{4,5}$. Eric Duku ${ }^{1} \cdot$ Mark A. Ferro $^{6} \cdot$ Barry Forer $^{7}$. Stelios Georgiades ${ }^{1}$. Jan Willem Gorter ${ }^{8,9}$. \\ Martin Guhn ${ }^{7}$ Jonathon Maguire ${ }^{4,10} \cdot$ Heather Manson ${ }^{11} \cdot$ Jacqueline Pei $^{12} \cdot$ Rob Santos $^{3} \cdot$ Robert J. Coplan $^{2}$
}

Accepted: 8 February 2022

(c) The Author(s) 2022

\begin{abstract}
Despite anxiety being a prevalent mental health problem in children, little data exist on the pervasiveness and levels of anxiety symptoms in kindergarteners. Data from the Early Development Instrument, a teacher-completed, population-level measure of child development, were collected across Canada from 2004 to 2015. The final analytic sample consisted of 974,319 children of whom $2.6 \%$ were classified as "highly anxious". Compared to children who exhibited "few to none" anxious behaviors, highly anxious children were more likely to be male, have English/French as a second language, and have a special needs designation. Furthermore, compared with their less anxious peers, highly anxious children had between 3.5 and 6.1 higher odds of scoring below the $10^{\text {th }}$ percentile cut-off in physical, social, language/cognitive and communication domains. Our findings suggest that anxious behaviors are related to children's overall health and illustrate the consistency and extensiveness of anxiety at a very young age among Canadian children.
\end{abstract}

Keywords Kindergarten $\cdot$ Anxiety $\cdot$ Early Development Instrument $\cdot$ Canada $\cdot$ Early child development

\section{Introduction}

Anxiety disorders are widely acknowledged to be among the most common psychological disorders for children and youth; they emerge and can be diagnosed as early as preschool age $[1,2]$. Notwithstanding, information regarding the prevalence of anxiety disorders during the early

Magdalena Janus

janusm@mcmaster.ca

1 Offord Centre for Child Studies, Department of Psychiatry and Behavioural Neuroscience, McMaster University, BAHT 132, 1280 Main St. West, Hamilton, ON L8S 4K1, Canada

2 Department of Psychology, Carleton University, Ottawa, ON, Canada

3 Department of Community Health Sciences, Manitoba Centre for Health Policy, University of Manitoba, Winnipeg, MB, Canada

4 Department of Pediatrics, University of Toronto, Toronto, ON, Canada

5 The Hospital for Sick Children, Toronto, ON, Canada

6 School of Public Health and Health Systems, University of Waterloo, Waterloo, ON, Canada childhood years is quite scarce compared to older children $[2,3]$. Lifetime prevalence rates for anxiety disorders in youth seem to span up to $22 \%[4,5]$, and at any given time, nearly $2-3 \%$ of children and youth meet criteria for an anxiety disorder [6, 7]. To date, the prevalence research in early childhood typically encompasses preschool children who meet complete diagnostic criteria for an anxiety disorder.

7 Human Early Learning Partnership, School of Population and Public Health, University of British Columbia, Vancouver, BC, Canada

8 Department of Pediatrics, McMaster University, Hamilton, ON, Canada

9 CanChild Centre for Childhood Disability Research, McMaster University, Hamilton, ON, Canada

10 Li Ka Shing Knowledge Institute, St. Michael's Hospital, Toronto, ON, Canada

11 Public Health Ontario, Toronto, ON, Canada

12 Department of Educational Psychology, University of Alberta, Edmonton, AB, Canada 
For instance, studies have shown prevalence rates of various anxiety disorders among $2-5$-year-old children ranging from 0.3 to $11 \%$ [3, 8, 9]. These studies typically involve non-psychiatric, community samples, and employ measures such as the Child Behavior Checklist (CBCL) [10], the Preschool Age Psychiatric Assessment (PAPA) [11], and clinical interviews [3]. For instance, Egger and Angold [3] completed a review of four prevalence studies from 1997 to 2006, all of which utilized non-psychiatric samples and a two-stage approach including the above mentioned questionnaires to identify high scorers followed by clinical interviews. These studies reported a range of specific anxiety disorder prevalence between 0.3 and 5\% [3]. In 2015, a population-based study was conducted in Germany recruiting families at school entry $(n=1564)$. Parents of preschool children completed a questionnaire of select items from the CBCL [10] and the DISYPS-II [12], and the prevalence of anxiety disorders ranged from 3.4 to $10.7 \%$ [13]. In 2021, a study in Norway recruited a large sample of parents of 4-year-olds $(n=3456)$ during routine check-ups [14]. Parents completed the PAPA [11] and prevalence rates between 0.12 and $0.32 \%$ for specific anxiety disorders were reported. Evidently, despite variation in reported prevalence rates across studies, anxiety is common among young children.

Moreover, anxiety in early childhood has consistently been linked to continued experiences of anxiety throughout childhood, adolescence, and adulthood [15-19], as well as to lower quality of life [20]. Importantly, researchers have shown that the occurrence of heightened but subclinical levels of anxiety actually exceeds that of formal anxiety disorders, while being equally impairing. For instance, Bell-Dolan, Last and Strauss [21] found that symptoms of anxiety were present in up to 20-30\% of non-clinical youths, and other studies have placed estimates ranging between $3 \%$ and $49 \%$ [21, 22]. Although there is a good deal of variation in these reported rates of anxiety symptoms, these findings clearly indicate that feeling anxious is a very common phenomenon among children and youth.

The substantive impact of subclinical anxiety in childhood, or non-diagnosed but maladaptive anxious emotion, is also evident. There is growing evidence to suggest that heightened symptoms of anxiety put children at risk for future anxiety and mood difficulties [23-27], and are associated with increased substance use in adolescence [28] and poor academic outcomes [25, 29]. Perhaps most consistently, anxiety symptoms appear to be detrimental to children's academic achievement [24-26, 29, 30]. Indeed, these negative trajectories for children with subclinical but elevated symptoms of anxiety parallel those for children with anxiety disorders [28]. The presence of anxiety among kindergarten age children appears to be of particular importance. Indeed, many researchers have focused attention on the developmental characteristics and qualities that children possess when they enter school, and how these attributes (sometimes referred to as school readiness) [31] impact their academic trajectories. Aspects of developmental health, such as academic, cognitive, and socio-emotional skills, are suggested to be necessary for the successful adaptation to school settings, such as the ability to learn, interact with peers and teachers, and follow classroom routines [31-33]. There has been a growing interest in the socioemotional contributors to children's development at school entry. For instance, Romano et al. [34] reported that anxiety and depression among Canadian kindergarten children were among several factors that significantly predicted math and reading levels in third grade. These researchers concluded that socioemotional factors in kindergarten acted as predictors for later school success. Similarly, Duchesne et al. [24] found that a group of kindergarteners with high levels of anxiety were at greater risk of high school non-completion, even when controlling for other significant risk factors like aggression, hyperactivity, academic achievement, and familial adversity, indicating that socioemotional functioning in kindergarten can be predictive of much later academic outcomes.

There are several well-studied tools available to assess anxiety among older children (i.e., 8 years of age and older). These include the Multidimensional Anxiety Scale for Children [35], the Screen for Child Anxiety and Related Emotional Disorders [36], and the Spence Children's Anxiety Scale [37]. These are questionnaire-based measures that ask questions specific to symptoms of anxiety, and can be completed by the child themselves, as well as by parents or teachers. For younger children, there are fewer well-established options to choose from. These include the parentreported Preschool Anxiety Scale [38] and relevant subscales from the Child Behavior Checklist [39], with both teacher and parent forms. Parent and teacher ratings have generally been found to have good agreement [40]. Unlike parents, however, teachers can report on behaviors observed in school, an environment that might cause some children to be anxious [41], making them a valuable source of information for anxiety in kindergarten children. The current study employed the Early Development Instrument (EDI) [31], a teacher-completed checklist that assesses several domains of developmental health including emotional maturity and encompasses anxiety.

The EDI was developed in the late 1990s, in consultation with educators, as a holistic, population-based measure of early child development [26]. Many studies have examined the psychometric properties of the EDI over the years, including construct validity [31, 42, 43], predictive validity [32, 44-46], between-group validity [47, 48], and cross-cultural validity [49-52]. All these studies have consistently demonstrated the validity and reliability of the EDI as a measure of early child development. The EDI includes an "anxious/fearful behaviour" subdomain targeting 
internalizing problems with mostly anxiety items that are very similar to those of other anxiety measures. Comparison of the prevalence obtained using the EDI resembles those from other studies [53], making it a good choice for evaluating mean levels of anxiety symptoms among kindergarten children. The added advantage of using the EDI in Canada is that data are collected at the population level, that is, for all children who attend publicly-funded kindergarten in a given year. Given the limited evidence on early symptoms of anxiety, the population-level coverage of the EDI, combined with methodological rigor, presents a unique opportunity to conduct a broad and extensive assessment of anxiety symptoms among young children.

\section{The Current Study}

To date, studies reporting prevalence rates of anxiety disorders in youth have varied tremendously. Some studies from around the world (US and Germany) reporting prevalence rates of anxiety in early childhood place estimates around $20 \%$ [13, 54], while Canadian figures seem to differ, with about $5 \%$ of youth being diagnosed with an anxiety disorder [55]. Using an early subset of the EDI data collected between 2005 and 2007 for just over 170,000 children, Janus [53] found that about 2-3\% of Canadian children in the 4-6-year-old range had elevated symptoms of anxiety. However, this study was a preliminary exploration of anxiety symptoms and data came from only 7 out of 13 provinces/ jurisdictions thus reflecting a smaller and less representative Canadian sample than the current study. To date, population-level studies of anxiety symptoms in young children remain scarce. Moreover, we know even less about basic questions, such as how anxiety in early childhood is related to demographic variables and other indices of developmental vulnerability. Accordingly, the primary objectives of this study were to: (1) determine teacher-reported mean levels of anxiety symptoms in kindergarten children attending publicly-funded schools across Canadian provinces and territories and their demographics; and (2) examine the associated developmental vulnerabilities among children who exhibit anxious symptoms in this Canadian population sample. Although the EDI does not provide clinical diagnoses of anxiety disorders, we speculated that the established cut off rate that identifies children as vulnerable in this domain (i.e., "highly-anxious" - see Method section for more details) would be consistent with previously established prevalence rates for anxiety in early childhood in Canada. Accordingly, it was hypothesized that about $2-5 \%$ of kindergarten children in Canada would meet the classification criteria for being highly anxious, with some variation across provinces (as a function of underlying differences in population demographics). In addition, based on the aforementioned research suggesting the impairment of anxiety extends to other emotional and academic domains, we also hypothesized that increased ratings of anxiety would be related to increased difficulties in the other developmental domains of the EDI, suggesting broad implications for developmental health. These findings will contribute to the developing body of evidence on anxiety among young children with a focus on a Canadian sample and potentially used for development of preventive strategies.

\section{Method}

\section{Study Population}

The study population includes all children attending publicly-funded schools whose teachers completed the EDI between 2004 and 2015. Teachers completed the EDI once for all the children enrolled in their class at the time of data collection. All EDI data collections from 2004 to 2015 include developmental outcomes along with demographic information for the children. The total study population consisted of 1,038,354 children for whom EDI records were collected in 12 of the 13 provinces and territories in Canada (with the exception of Nunavut). The study received approval from the Hamilton Integrated Research Ethics Board (\#2403).

Kindergarten in Canada is the school year before entry to Grade 1, and it is the grade children start the year they turn 5 years old. The vast majority of Canadian children attend publicly-funded schools (91.8\% in 2018/19) [56]. Data were collected in the second half of the school year. Data collection occurred in each province/territory ${ }^{1}$ between 1 and 5 times in either a single year or in 2-5-year waves, where a subset of the population was sampled each year until full provincial coverage was achieved (see Table 1). In addition to the ratings on child development, the database includes the following demographic information for each child: age (at time of data collection), sex (male/female), whether they have English/French as a Second Language (E/FSL; yes/no), and whether they have been identified with a special health need (SN; yes/no).

\section{Inclusion Criteria}

The following inclusion criteria were applied: (1) the child was enrolled in kindergarten; (2) the child was in the classroom for at least one month; and (3) there was no more

\footnotetext{
${ }^{1}$ Each jurisdiction funds its own population-level data collection and decides the frequency of data collections for their province/territory. The timing of the different collections is therefore out of the authors' control.
} 
Table 1 Canadian EDI implementation schedule from 2004 to 2015 with number of children in each implementation

\begin{tabular}{|c|c|c|c|c|c|c|c|c|c|c|c|c|}
\hline & $\mathrm{AB}$ & $\mathrm{BC}$ & MB & NB & $\mathrm{NL}$ & NT & NS & ON & PEI & QC & SK & $\mathrm{Y}$ \\
\hline 2004 & & & & & & & & 118,903 & & & & \\
\hline 2005 & 2449 & 35,369 & 8387 & 678 & & & & & & 1620 & 3073 & \\
\hline 2006 & & & 11,671 & 784 & & & 1520 & & & 11,186 & 1280 & \\
\hline 2007 & & & 11,514 & 383 & & & & 115,952 & & 1394 & 1538 & \\
\hline 2008 & 191 & 37,213 & 1418 & & 340 & & 456 & & 1090 & 876 & 1580 & \\
\hline 2009 & 72,681 & & 11,516 & 6996 & & & 4833 & & & 2519 & 22,320 & \\
\hline 2010 & & 46,243 & & & & & 746 & 124,743 & & & & 336 \\
\hline 2011 & & & 11,819 & & 1088 & & 2295 & & & & & 340 \\
\hline 2012 & & 42,033 & & & 2089 & 581 & 2197 & & & 56,989 & 538 & 362 \\
\hline 2013 & & & 12,873 & & 4833 & 606 & 8394 & & & & 7943 & 399 \\
\hline 2014 & & 1277 & & & 5060 & 606 & 1375 & & & & & \\
\hline 2015 & & & 13,196 & & & 595 & 8504 & 132,719 & & & & \\
\hline
\end{tabular}

Bold font in cells indicates a full provincial collection; if the cell spans multiple years it means a province or territory completed the implementation in waves. Regular font in cells indicates a partial provincial collection

$A B$ Alberta, $B C$ British Columbia, $M B$ Manitoba, $N B$ New Brunswick, $N L$ Newfoundland and Labrador, $N T$ Northwest Territories, NS Nova Scotia, ON Ontario, PEI Prince Edward Island, $Q C$ Quebec, SK Saskatchewan, $Y$ Yukon

\begin{tabular}{lccc}
\hline Variable & Full population $(\mathrm{N}=990,502)$ & $\begin{array}{l}\text { Excluded from analyses } \\
(\mathrm{N}=16,183)\end{array}$ & $\begin{array}{l}\text { Final analytic sam- } \\
\text { ple }(\mathrm{N}=974,319)\end{array}$ \\
\hline \% Male & 51.3 & 52.0 & 51.3 \\
Mean age (SD) & $5.71(.32)$ & $5.69(.34)$ & $5.71(.32)$ \\
$\%$ E/FSL & 13.0 & 19.4 & 12.9 \\
$\%$ Special needs & 3.6 & 8.1 & 3.6 \\
$\%$ Anxious & 2.6 & 4.1 & 2.6 \\
\hline
\end{tabular}

Table 2 Descriptive statistics of the full population and final analytic sample broken down into 16 subdomains. The structure of the EDI subdomains within the domains has been confirmed through factor analysis [57]. In particular, the emotional maturity domain contains 30 items divided into the following subdomains: (1) prosocial and helping behavior; (2) anxious and fearful behavior; (3) aggressive behavior; and (4) hyperactivity and inattention. A mean score, from 0 to 10 , is calculated for all domains and subdomains, with a higher score indicating greater ability [57]; thus, a high score on the anxious/ fearful behavior subdomain means that a child shows few (or none) of those behaviors, while a low score means that they exhibit many of them.

There are two main sets of outcome variables based on the EDI data: the domain mean scores and vulnerability. Vulnerability was used as the dependent variable in the current study. After a jurisdiction collects EDI data at the population-level for the first time, the children's scores are ranked and then used to create cut-offs. A child is considered to be vulnerable in a given domain if their score falls below the 10th percentile distribution cut-off [57]. Vulnerability on one or more domains has proven to be highly predictive of children's achievement in later grades (e.g., [46, 58, 59]), as 
well as meaningful for jurisdictional comparisons in other countries [60].

The independent variable in this study was measured by the anxious and fearful behavior subdomain that is one of four subdomains contributing to the domain of Emotional maturity (8 items: upset when left by parent/guardian; seems to be unhappy, sad, or depressed; appears fearful or anxious; appears worried; cries a lot; nervous, high-strung, or tense; incapable of making decisions; shy; see Appendix 1 for factor loadings) representing symptoms of anxiety. The EDI's Emotional maturity "anxiety and fearful behaviour" subdomain, which represents a broader concept of "internalizing" behaviours, was designed based on items commonly found in established anxiety measures and narrowed down to those that would be most appropriate for children aged between 3.5 and 6.5 years. For example, similar items can be found on relevant scales from the Child Behavior Checklist (CBCL, e.g., "cries a lot", "worries", "shy or timid") [61] and the Strength and Difficulties Questionnaire (SDQ, e.g., "many worries or often seems worried", "many fears, easily scared") [62]. Due to the EDI's explicit aim to provide a holistic, broad measure of child development, and not be used for clinical assessment, there are no explicit validity studies of the subdomains that would have been required for a diagnostic use of the subdomain scores.

Each of the subdomains has an empirically based threshold [57] that reflects whether the child meets the developmental expectations for the subdomain or not. These thresholds were developed in consultation with educators, early years professionals, and academics working in the field of early childhood development to facilitate the use of the EDI results by stakeholders. Behavioural profiles were developed for school districts based on reviewing the frequencies of item endorsement for children who scored below the 10th percentile vulnerability cut-off for a given domain. This was then subjected to a focus group with kindergarten teachers and an in-person consultation with three child developmental clinicians (one child psychiatrist and two child psychologists). Once agreements were achieved, the score equivalent to the specific endorsement frequencies was calculated. For the anxious/fearful behavior subdomain, this score represents a child who exhibits at least half of the anxious and fearful behaviors "often," or most of these behaviors (at least 7 out of 8) "sometimes." Therefore, a child was deemed to meet few or none of the developmental expectations if their mean score was equal to or lower than 4.999 [57]. This threshold was considered to reflect the top of "the lowest range" of developmental skills children should possess in order to present as "ready to learn at school."

For the purpose of this study, a child was classified as anxious if his/her score was below the subdomain threshold. In support of this approach, Janus [53] reported that this method yielded prevalence rates of anxiety comparable with previously established levels in the extant literature. The subdomain was originally derived based on a factor analysis of the emotional maturity domain in the Normative EDI database $(N=160,000)$ [57], with an internal consistency of Cronbach's $\alpha=0.808$. A Confirmatory Factor Analysis (CFA) was performed on the current dataset, with factor loadings reported in Appendix 1. The internal consistency of the subdomain in the present study population was Cronbach's $\alpha=0.799$.

\section{Analytic Plan}

Demographic characteristics and domain vulnerability rates were then examined between anxious and non-anxious children, using chi-square statistics and Cramer's V to examine effect sizes. In order to examine the association between anxiety and children's concurrent development in four domains (physical, social, language/cognitive, and communication), unadjusted and adjusted binary logistic regressions were conducted, controlling for sex, age, E/FSL status, SN designation, as well as province and year of data collection. The first four variables are individual child characteristics shown to have strong associations with child development at school entry. Province and year of data collection were added to adjust for any variation in the timing and nature of the data collection initiatives. IBM SPSS Statistics, version 25 [63] was used for all analyses and we employed a level of significance of $p=0.004$ for our hypothesis testing, using the Bonferroni correction.

\section{Results}

\section{Prevalence and Demographics}

There was a total of $25,262(2.6 \%)$ kindergarten children classified as anxious in Canada. The prevalence of anxiety was significantly different between jurisdictions $\left(\chi^{2}(11)=462.738, p<0.001\right)$, ranging from $1.1 \%$ in Prince Edward Island (PEI) to $5.0 \%$ in Northwest Territories. To investigate whether the prevalence of anxiety was significantly different between individual provinces/territories and the remaining population, province/territory was dummy coded. Although the percentage of anxious children was significantly lower than the national average in four provinces (PEI, Newfoundland, Saskatchewan, Ontario) and significantly higher than the national average in three provinces (Nova Scotia, British Columbia, Northwest Territories), the effect sizes for these differences were all very small (Cramer's $V<0.017$, see Table 3). Results from a one-way analysis of variance (ANOVA) determined that the prevalence of anxiety was significantly different across EDI years (ranging from 2.1 to $3.0 \%$ per year $(F(1,974,317)=238.0, p<0.001)$, 
Table 3 Chi-square tests (with effect sizes, using Cramer's V) of the prevalence of anxious children by province/territory
Table 4 Demographic characteristics and vulnerability rates in four EDI domains among anxious and non-anxious children

\begin{tabular}{lclrr}
\hline Province & $\begin{array}{l}\text { Number (\%) of children with } \\
\text { anxiety symptoms }\end{array}$ & $\begin{array}{l}\text { Total number of } \\
\text { children }\end{array}$ & $\chi^{2}$ & Cramer's V \\
\hline PEI & $12(1.1)$ & 1075 & $9.29^{*}$ & 0.003 \\
Newfoundland & $213(1.6)$ & 13,294 & $52.36^{*}$ & 0.007 \\
Saskatchewan & $841(2.2)$ & 37,915 & $21.93^{*}$ & 0.005 \\
Ontario & $11,660(2.4)$ & 482,852 & $120.04^{*}$ & 0.011 \\
Manitoba & $2087(2.6)$ & 80,994 & 0.09 & $<0.001$ \\
Quebec & $2130(2.6)$ & 81,506 & 0.15 & $<0.001$ \\
Alberta & $1910(2.6)$ & 74,862 & 0.55 & 0.001 \\
New Brunswick & $233(2.7)$ & 8651 & 0.35 & 0.001 \\
Nova Scotia & $871(2.9)$ & 29,848 & $12.90^{*}$ & 0.004 \\
British Columbia & $5139(3.2)$ & 159,532 & $298.38^{*}$ & 0.017 \\
Yukon & $48(3.4)$ & 1423 & 3.44 & 0.002 \\
Northwest Territories & $118(5.0)$ & 2367 & $53.77^{*}$ & 0.007 \\
\hline
\end{tabular}

$* p<0.004$, corrected for multiple comparisons

\begin{tabular}{llrrr}
\hline & Anxious \% & Non-Anxious \% & \multicolumn{1}{c}{$\chi^{2}$} & Cramer's V \\
\hline Demographics & & & & \\
Male & 55.4 & 51.2 & $178.1^{*}$ & 0.014 \\
SN & 11.1 & 3.4 & $4210.0^{*}$ & 0.066 \\
E/FSL & 14.2 & 12.9 & $37.9^{*}$ & 0.006 \\
Developmental domain vulnerability & & & & \\
$\quad$ Physical & 43.1 & 11.3 & $23,446.6^{*}$ & 0.155 \\
Social & 42.6 & 10.3 & $26,016.3^{*}$ & 0.163 \\
Language-cognitive & 27.8 & 8.8 & $10,555.8^{*}$ & 0.104 \\
Communication and general knowledge & 42.8 & 13.2 & $18,029.4^{*}$ & 0.136 \\
\hline
\end{tabular}

$* p<0.004$, corrected for multiple comparisons however the effect size was very small $\left(\eta^{2}<0.001\right)$ and there was neither an increasing or decreasing pattern over time.

The demographic characteristics of anxious children are presented in Table 4. Compared to their non-anxious peers, anxious children were significantly more likely to be male, have a SN designation, and have E/FSL. Anxious children were also younger than non-anxious children (5.68 vs 5.71 years) as determined by a one-way ANOVA $\left(F(1,974,317)=238.0, p<0.001, \eta^{2}<0.001\right)$, however the effect size was very small.

\section{Anxiety and Vulnerability in Other Areas of Development}

Overall, anxious children were significantly more likely than their non-anxious counterparts to be vulnerable in four domains of the EDI: physical, social, language/cognitive, and communication (Table 4). We then examined the magnitude of this relationship by conducting logistic regression, acknowledging that this was purely an analysis of association as the domains are correlated with each other with coefficients ranging from 0.47 to 0.63 , except for the one between emotional maturity and social competence, which was 0.80 . Table 5 shows results of the unadjusted and adjusted binary logistic regressions odds ratios, adjusted odds ratios (controlling for children's sex, age, E/FSL, SN status, province/territory, and year of data collection), as well as corresponding 95\% confidence intervals (CIs) for child anxiety and vulnerability on four EDI domains (all but emotional maturity). Anxious children had 3.5 to 6.1 times higher odds of being vulnerable in these domains, compared to their non-anxious counterparts.

\section{Discussion}

This study provided the first pan-Canadian snapshot of anxiety symptoms among Canadian children at school entry. Prevalence varied somewhat across Canadian jurisdictions, ranging from $1.1 \%$ in PEI to $5.0 \%$ in Northwest Territories. Our results confirm the hypothesis that the prevalence of anxiety would be comparable to epidemiological 
Table 5 Binary logistic regression analyses examining the associations between child anxiety and vulnerability in the four developmental domains of the EDI

\begin{tabular}{lll}
\hline Developmental domain & $\begin{array}{l}\text { Unadjusted odds ratio (95\% } \\
\text { CI) }\end{array}$ & $\begin{array}{l}\text { Adjusted odds } \\
\text { ratio (95\% CI) }\end{array}$ \\
\hline Physical health and well-being & $5.96(5.81-6.12)$ & $5.44(5.29-5.59)$ \\
Social competence & $6.48(6.32-6.65)$ & $6.14(5.97-6.31)$ \\
Language and cognitive development & $3.99(3.88-4.11)$ & $3.46(3.35-3.56)$ \\
Communication and general knowledge & $4.94(4.81-5.06)$ & $4.93(4.79-5.07)$ \\
\hline
\end{tabular}

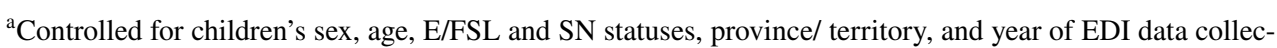
tion sample-based studies of children of comparable age (i.e., $2-3 \%$ from [53]).

We also investigated demographic trends in variation of anxiety symptoms, including age, sex, E/FSL, SN status, and region (province/territory). Children identified as highly anxious tended to be younger and were more likely to be male than their non-anxious counterparts. However, it should be noted that although both of these differences were statistically significant, the effect sizes were quite small. Since anxiety has been consistently documented in this age range, the age effects here likely represent minor differences in anxiety among a single grade year, rather than a broad age-based effect. In other words, we can use these data to predict that students who are younger than their peers may be more prone to demonstrating anxiety in the classroom for factors related to development and maturity. In terms of sex, anxiety has typically been found to be more prevalent among females than males across the lifespan (e.g. [64-66]), but this effect has not always been found (e.g. [67, 68]), and some suggest it may only emerge in adolescence $[69,70]$. Our data suggest that the higher prevalence of anxiety in females may not be present in the early childhood age range, and if anything, indicate a possibility of the reverse pattern.

Anxious children also tended to have SN and E/FSL at a higher rate than their non-anxious counterparts. Indeed, the associations between anxiety and second language learning, as well as between anxiety and $\mathrm{SN}$, have been well documented to date (e.g., [71-75]). For instance, researchers have found higher incidences of anxiety among children with intellectual delays [74, 76] and with autism [77, 78]. Although various factors have been attributed to this phenomenon, emotional problems that co-occur with these disorders seem likely (e.g. [79-81]). With regard to second language learning and anxiety, this phenomenon has been attributed to various possible causes, such as communication apprehension and fear of negative evaluation [82], stressful classroom experiences and perception of language aptitude [83], as well as various interactions between the teacher, the learner, and the classroom [84, 85]. Regardless of the possible explanations, our data provide further evidence that young children with $\mathrm{SN}$ or those who are learning in a second language demonstrate higher levels of anxiety in the classroom.

Another notable finding is that prevalence of highly anxious children differed between provinces/ territories, though with only a small effect size. This may be due, at least in part, to provincial/territorial differences around teacher familiarity with these constructs, or systemic differences in the education settings. First, education in Canada is placed within a provincial, rather than a federal jurisdiction, and thus teacher training and curricula vary across the country. In addition, the kindergarten structure also varies widely across Canada, from half day, to full day part-time, to full day, every day. In fact, in our sample, Ontario instituted a change to make full day kindergarten available during the 3rd cohort (representing about a quarter of the total Ontario sample). Indeed, this sort of schedule change could impact teacher ratings of children's anxious behavior due to teachers spending more time with students and having more opportunities to observe them. Perhaps relatedly, we found a small, but statistically significant effect of cohort (year of study), pointing to the possibility that these types of changes may affect anxiety ratings in students. Together, these results suggest that it may be useful to conduct future studies that focus on cohort effects and region-specific factors that may be at play.

We also examined the links between anxiety and other aspects of developmental health. Our results demonstrate that having symptoms of anxiety is not benign: children with elevated symptoms of anxiety are three to six times more likely to be vulnerable on other domains of development, that is, physical, social, language/cognitive, and communication skills, than those who exhibit very few of these symptoms. This finding supports the notion that anxiety and other aspects of development, as well as skill acquisition and use, are closely intertwined, and further promotes a holistic view of developmental health that includes socio-emotional functioning.

\section{Strengths and Limitations}

This study is an extensive examination of anxiety symptoms among kindergarten students in Canada, a first national 
investigation in this age group. A large sample was used with a robust method of population-based data collection with developmentally appropriate instrument that enhances representativeness, and that is comparable to other behavioral assessments in this age group. In addition, the data allowed us to examine region-specific prevalence rates of anxiety, which can provide important information for policy. The inclusion of other domains of developmental health in conjunction with anxiety prevalence is also a unique contribution, highlighting the importance of anxiety in the context of developmental health more broadly.

Even though our study population represents a large proportion of children attending publicly-funded kindergarten classes, the children studied here do not represent all kindergarten-aged children in Canada. About 92\% of school aged children are enrolled in public schools across Canada [86], and so children who attend private school or are home-schooled are not included in the current sample. In addition, the children included here varied in type of kindergarten setting (full day or half day, every day or every other day). The difficulty with addressing program type is that it is confounded by province/territory. Because kindergarten programs are implemented at the provincial level, controlling for province/territory in our analyses also accounted for program type. Previous research suggests that the association between type of care a child receives and child anxiety is a complex and non-linear relation that appears to vary as a function of both quantity and type of care (e.g., [87]). This makes it difficult to ascertain how the results of the current study might have been influenced by full- versus half-day kindergarten experiences, or whether anxiety among children who are home schooled or in private schooling may differ from the children included here. Targeting these questions in future studies would be helpful in determining risk and protector factors in the presentation of anxiety symptoms among kindergarten age children.

The anxiety measure used here has not been explicitly tested for convergent or discriminant validity with diagnostic tools, although it includes items very similar to those used in such tools (e.g., [61, 62]). This study includes a single rater, observer-based assessments of anxiety, limiting the interpretation of this prevalence data. Using observerbased ratings exclude internalizing factors that may not be noticeable to the informant. Similarly, relying on teacher reports excludes anxious behavior that may be occurring at home, as reported by parents. Teacher reports do provide meaningful information about student behavior in school, an important domain of functioning, providing relevance to the examination of these symptoms as displayed and observable in a developmentally-relevant context. Therefore, the data presented here do not provide a comprehensive view of a child's anxious behaviors and symptoms across different settings, but rather an estimate of anxious behaviors among children in a specific academic setting. While the EDI is not a screening tool, the experience of completing it does alert the teacher to potential difficulties a child may face and thus could be used as a basis for further assessment with clinically validated measures of anxiety to determine the severity of the issue and need for intervention.

\section{Summary}

In this first population-wide study of anxiety symptoms in young Canadian children, we found slight differences across provinces and territories, with a national prevalence average of $2.6 \%$. We also found that rates were fairly stable over the years, with slight variations. Symptoms of anxiety in kindergarten children, as reported by their teachers, were associated with increased odds of being vulnerable in other areas of their development which indicates that children who are anxious are more likely to also struggle in those areas than their non-anxious counterparts. Altogether, the current study demonstrates the feasibility of using the EDI data to monitor anxiety, as displayed at school, in kindergarten children.

Early identification is a crucial step in providing early intervention and prevention programs for young anxious children that attempts to mitigate the long-term impact of anxiety. In recent years, several efficacious programs have been developed targeting young children vulnerable to early anxiety (e.g., high in behavioral inhibition) (see [88] for a recent review). These include parental education and training programs (e.g., Cool Little Kids, [89]) and multicomponent interventions that also incorporate social skills training (e.g., Turtle Program, [90]). In jurisdictions that implement the EDI on a regular basis, the frequency of anxiety symptoms on the questionnaire can be used to monitor the impact of interventions employed in preschools. Schools with children with high frequencies of anxiety symptoms may be advised to put into practice class-level activities to mitigate long-term consequences of kindergarten anxiety.

In future, corroboration of these prevalence rates by including parent-ratings would be useful. Similarly, validating the use of the EDI as a measure of anxiety would be a worthwhile next step, such as by including diagnostic interviews to confirm anxiety symptom levels and diagnostic status. Finally, this study provides "baseline" estimates of anxiety symptoms among kindergarten-aged children in Canada, which could, in future, be compared to data collected with the same method among the post-COVID-19 cohorts of kindergarten-age students across Canada.

Supplementary Information The online version contains supplementary material available at https://doi.org/10.1007/s10578-022-01332-9. 
Acknowledgements We would like to thank all our provincial and territorial partners for their hard work and commitment to the EDI data collections, as well as all the teachers who committed their time and energy in completing the EDI questionnaires over the years.

Funding This work was supported by an operating grant from the Canadian Institutes of Health Research, Grant Number 142416.

\section{Declarations}

Conflict of interest The authors declare that they have no conflict of interest.

Ethical Approval All procedures performed in studies involving human participants were in accordance with the ethical standards of the institutional and/or national research committee and with the 1964 Helsinki declaration and its later amendments or comparable ethical standards.

Informed Consent For this type of study, formal consent is not required.

Open Access This article is licensed under a Creative Commons Attribution 4.0 International License, which permits use, sharing, adaptation, distribution and reproduction in any medium or format, as long as you give appropriate credit to the original author(s) and the source, provide a link to the Creative Commons licence, and indicate if changes were made. The images or other third party material in this article are included in the article's Creative Commons licence, unless indicated otherwise in a credit line to the material. If material is not included in the article's Creative Commons licence and your intended use is not permitted by statutory regulation or exceeds the permitted use, you will need to obtain permission directly from the copyright holder. To view a copy of this licence, visit http://creativecommons.org/licenses/by/4.0/.

\section{References}

1. Achenbach TM, Howell CT, Mcconaughy SH, Stanger C (1995) Six-year predictors of problems in a national sample of children and youth: II. Signs of disturbance. J Am Acad Child Adolesc Psychiatry 34:488-498. https://doi.org/10.1097/00004583-19950 4000-00016

2. Costello EJ, Egger HL, Angold A (2005) The developmental epidemiology of anxiety disorders: phenomenology, prevalence, and comorbidity. Child Adolesc Psychiatr Clin N Am 14:631-648. https://doi.org/10.1016/j.chc.2005.06.003

3. Egger HL, Angold A (2006) Common emotional and behavioral disorders in preschool children: presentation, nosology, and epidemiology. J Child Psychol Psychiatry 47:313-337. https://doi. org/10.1111/j.1469-7610.2006.01618.x

4. Beesdo K, Knappe S, Pine DS (2009) Anxiety and anxiety disorders in children and adolescents: developmental issues and implications for DSM-V. Psychiatr Clin North Am 32:483-524. https:// doi.org/10.1016/j.psc.2009.06.002

5. Costello EJ, Egger HL, Angold A (2004) Developmental Epidemiology of Anxiety Disorders. In: Ollendick TH, March JS (eds) Phobic and Anxiety Disorders in Children and Adolescents: A Clinician's Guide to Effective Psychosocial and Pharmacological Interventions. Oxford University Press, New York, NY, pp 61-91

6. Costello EJ, Mustillo S, Erkanli A, Keeler G, Angold A (2003) Prevalence and development of psychiatric disorders in childhood and adolescence. Arch Gen Psychiatry 60:837-844. https://doi. org/10.1001/archpsyc.60.8.837

7. Ford T, Goodman R, Meltzer H (2003) The British child and adolescent mental health survey 1999: the prevalence of DSM-IV disorders. J Am Acad Child Adolesc Psychiatry 42:1203-1211. https://doi.org/10.1097/00004583-200310000-00011

8. Keenan K, Shaw DS, Walsh B, Delliquadri E, Giovannelli J (1997) DSM-III-R disorders in preschool children from low-income families. J Am Acad Child Adolesc Psychiatry 36:620-627. https://doi. org/10.1097/00004583-199705000-00012

9. Lavigne JV, LeBailly SA, Hopkins J, Gouze KR, Binns HJ (2009) The prevalence of ADHD, ODD, depression, and anxiety in a community sample of 4-year-olds. J Clin Child Adolesc Psychol 38:315-328. https://doi.org/10.1080/15374410902851382

10. Achenbach TM (1999) The Child Behavior Checklist and related instruments. In: The use of psychological testing for treatment planning and outcomes assessment, 2nd ed. Lawrence Erlbaum Associates Publishers, Mahwah, NJ, pp 429-466

11. Egger HL, Angold A (2004) The Preschool Age Psychiatric Assessment (PAPA): A Structured Parent Interview for Diagnosing Psychiatric Disorders in Preschool Children. Handbook of infant, toddler, and preschool mental health assessment. Oxford University Press, New York, NY, pp 223-243

12. Döpfner MV, Görtz-Dorten A, Lehmkuhl G (2008) DISYPS-II - Diagnostik-System für psychische Störungen nach ICD-10 und DSM-IV für Kinder und Jugendliche - II - Hogrefe Verlag. Verlag Hans-Huber, Bern

13. Paulus FW, Backes A, Sander CS, Weber M, von Gontard A (2015) Anxiety disorders and behavioral inhibition in preschool children: a population-based study. Child Psychiatry Hum Dev 46:150-157. https://doi.org/10.1007/s10578-014-0460-8

14. Steinsbekk S, Ranum B, Wichstrøm L (2021) Prevalence and course of anxiety disorders and symptoms from preschool to adolescence: a 6-wave community study. J Child Psychol Psychiatry. https://doi.org/10.1111/jcpp.13487

15. Bittner A, Egger HL, Erkanli A, Costello EJ, Foley DL, Angold A (2007) What do childhood anxiety disorders predict? J Child Psychol Psychiatry 48:1174-1183. https://doi.org/10.1111/j.14697610.2007.01812.x

16. Copeland WE, Shanahan L, Costello EJ, Angold A (2009) Childhood and adolescent psychiatric disorders as predictors of young adult disorders. Arch Gen Psychiatry 66:764. https://doi.org/10. 1001/archgenpsychiatry.2009.85

17. Goodwin RD, Fergusson DM, Horwood LJ (2004) Early anxious/ withdrawn behaviours predict later internalising disorders. J Child Psychol Psychiatry 45:874-883. https://doi.org/10.1111/j.14697610.2004.00279.x

18. Kagan J, Snidman N (1999) Early childhood predictors of adult anxiety disorders. Biol Psychiat 46:1536-1541. https://doi.org/10. 1016/S0006-3223(99)00137-7

19. Muris P, van Brakel AML, Arntz A, Schouten E (2011) Behavioral inhibition as a risk factor for the development of childhood anxiety disorders: a longitudinal study. J Child Fam Stud 20:157-170. https://doi.org/10.1007/s10826-010-9365-8

20. Ramsawh HJ, Chavira DA (2016) Association of childhood anxiety disorders and quality of life in a primary care sample. J Dev Behav Pediatr 37:269-276. https://doi.org/10.1097/DBP.00000 00000000296

21. Bell-Dolan DJ, Last CG, Strauss CC (1990) Symptoms of anxiety disorders in normal children. J Am Acad Child Adolesc Psychiatry 29:759-765. https://doi.org/10.1097/00004583-19900 9000-00014

22. Abe K, Masui T (1981) Age-sex trends of phobic and anxiety symptoms in adolescents. Br J Psychiatry 138:297-302. https:// doi.org/10.1192/bjp.138.4.297 
23. Broeren S, Muris P, Diamantopoulou S, Baker JR (2013) The course of childhood anxiety symptoms: developmental trajectories and child-related factors in normal children. J Abnorm Child Psychol 41:81-95. https://doi.org/10.1007/s10802-012-9669-9

24. Duchesne S, Vitaro F, Larose S, Tremblay RE (2008) Trajectories of anxiety during elementary-school years and the prediction of high school noncompletion. J Youth Adolesc 37:1134-1146. https://doi.org/10.1007/s10964-007-9224-0

25. Grover RL, Ginsburg GS, Ialongo N (2007) Psychosocial outcomes of anxious first graders: a seven-year follow-up. Depress Anxiety 24:410-420. https://doi.org/10.1002/da.20241

26. Ialongo N, Edelsohn G, Werthamer-Larsson L, Crockett L, Kellam S (1995) The significance of self-reported anxious symptoms in first grade children: prediction to anxious symptoms and adaptive functioning in fifth grade. J Child Psychol Psychiatry 36:427-437. https://doi.org/10.1111/j.1469-7610.1995.tb01300.x

27. Weems CF (2008) Developmental trajectories of childhood anxiety: Identifying continuity and change in anxious emotion. Dev Rev 28:488-502. https://doi.org/10.1016/j.dr.2008.01.001

28. Kendall PC, Safford S, Flannery-Schroeder E, Webb A (2004) Child anxiety treatment: outcomes in adolescence and impact on substance use and depression at 7.4-year follow-up. J Consult Clin Psychol 72:276-287. https://doi.org/10.1037/0022-006X. 72.2 .276

29. Owens M, Stevenson J, Hadwin JA, Norgate R (2012) Anxiety and depression in academic performance: an exploration of the mediating factors of worry and working memory. Sch Psychol Int 33:433-449. https://doi.org/10.1177/0143034311427433

30. Woodward LJ, Fergusson DM (2001) Life course outcomes of young people with anxiety disorders in adolescence. J Am Acad Child Adolesc Psychiatry 40:1086-1093. https://doi.org/10.1097/ 00004583-200109000-00018

31. Janus M, Offord DR (2007) Development and psychometric properties of the Early Development Instrument (EDI): a measure of children's school readiness. Can J Behav Sci/Revue Canadienne Des Sciences du Comportement 39:1-22. https://doi.org/10.1037/ cjbs2007001

32. Forget-Dubois N, Lemelin J-P, Boivin M, Dionne G, Séguin JR, Vitaro F et al (2007) Predicting early school achievement with the EDI: a longitudinal population-based study. Early Educ Dev 18:405-426. https://doi.org/10.1080/10409280701610796

33. Pinto G, Bigozzi L, Tarchi C, Vezzani C, Accorti Gamannossi B (2016) Predicting reading, spelling, and mathematical skills: a longitudinal study from kindergarten through first grade. Psychol Rep 118:413-440. https://doi.org/10.1177/0033294116633357

34. Romano E, Babchishin L, Pagani LS, Kohen D (2010) School readiness and later achievement: replication and extension using a nationwide Canadian survey. Dev Psychol 46:995-1007. https:// doi.org/10.1037/a0018880

35. March JS, Parker JDA, Sullivan K, Stalling P, Conners CK (1997) The Multidimensional Anxiety Scale for Children (MASC): factor structure, reliability, and validity. J Am Acad Child Adolesc Psychiatry 36:554-565. https://doi.org/10.1097/00004583-19970 4000-00019

36. Birmaher B, Khetarpal S, Brent D, Cully M, Balach L, Kaufmann J et al (1997) The Screen for Child Anxiety Related Emotional Disorders (SCARED): scale construction and psychometric characteristics. J Am Acad Child Adolesc Psychiatry 36:545-553. https://doi.org/10.1097/00004583-199704000-00018

37. Spence SH (1998) A measure of anxiety symptoms among children. Behav Res Ther 36:545-566. https://doi.org/10.1016/S00057967(98)00034-5

38. Spence SH, Rapee R (1999) Preschool Anxiety Scale (Parent Report and Teacher Version). https://www.scawebsite.com/docs/ scas-preschool-scale.pdf
39. Achenbach TM (2009) The Achenbach System of Empirically Based Assessment (ASEBA): Development, Findings, Theory, and Applications. Research Center for Children, Youth, and Families, Burlington, VT

40. Miller LD, Martinez YJ, Shumka E, Baker H (2014) Multiple informant agreement of child, parent, and teacher ratings of child anxiety within community samples. Can J Psychiatry 59:34-39. https://doi.org/10.1177/070674371405900107

41. Adams D, Simpson K, Keen D (2018) School-related anxiety symptomatology in a community sample of primary-school-aged children on the autism spectrum. J Sch Psychol 70:64-73. https:// doi.org/10.1016/j.jsp.2018.07.003

42. Hymel S, LeMare L, McKee W (2011) The Early Development Instrument: an examination of convergent and discriminant validity. Soc Indic Res 103:267-282

43. Guhn M, Zumbo BD, Janus M, Hertzman C (2011) Validation theory and research for a population-level measure of children's development, wellbeing, and school readiness. Soc Indic Res 103:183-191. https://doi.org/10.1007/s11205-011-9841-6

44. Davies S, Janus M, Duku E, Gaskin A (2016) Using the Early Development Instrument to examine cognitive and non-cognitive school readiness and elementary student achievement. Early Childhood Res Q 35:63-75. https://doi.org/10.1016/j.ecresq.2015. 10.002

45. Davies S, Janus M, Reid-Westoby C, Duku E, Schlanger P (2021) Does the Early Development Instrument predict academic achievement in Ontario French schools? Can J Behav Sci/Revue Canadienne des Sciences du Comportement. https://doi.org/10. $1037 / \mathrm{cbs} 0000285$

46. Duncan RJ, Duncan GJ, Stanley L, Aguilar E, Halfon N (2020) The kindergarten Early Development Instrument predicts third grade academic proficiency. Early Childhood Res Q 53:287-300. https://doi.org/10.1016/j.ecresq.2020.05.009

47. Muhajarine N, Puchala C, Janus M (2011) Does the EDI equivalently measure facets of school readiness for Aboriginal and nonAboriginal children? Social Indicators Res 103:299-314

48. Guhn M, Gadermann A, Zumbo BD (2007) Does the EDI measure school readiness in the same way across different groups of children? Early Educ Dev 18:453-472. https://doi.org/10.1080/ 10409280701610838

49. Georg S, Bosle C, Fischer JE, De Bock F (2020) Psychometric properties and contextual appropriateness of the German version of the Early Development Instrument. BMC Pediatr 20:339. https://doi.org/10.1186/s12887-020-02191-w

50. Brinkman SA, Kinnell A, Maika A, Hansan A, Jung A, Pradhan M (2017) Validity and reliability of the Early Development Instrument in Indonesia. Child Ind Res 10:331-352. https://doi.org/10. 1007/s12187-016-9372-4

51. Ip P, Li SL, Rao N, Ng SSN, Lau WWS, Chow CB (2013) Validation study of the Chinese Early Development Instrument (CEDI). BMC Pediatr 13:146. https://doi.org/10.1186/1471-2431-13-146

52. Janus M, Brinkman SA, Duku EK (2011) Validity and psychometric properties of the Early Development Instrument in Canada, Australia, United States, and Jamaica. Soc Indic Res 103:283. https://doi.org/10.1007/s11205-011-9846-1

53. Janus M (2010) Estimating prevalence of behaviour problems in kindergarten children based on population-level data. In: Proceedings of the XIV European Conference on Developmental Psychology. Medimond International Proceedings, Bologna, Italy, pp 193-198

54. Franz L, Angold A, Copeland W, Costello EJ, Towe-Goodman N, Egger H (2013) Preschool anxiety disorders in pediatric primary care: prevalence and comorbidity. J Am Acad Child Adolesc Psychiatry 52:1294-1303.e1. https://doi.org/10.1016/j.jaac.2013.09. 008 
55. Butler MA, Pang M (2014) Current issues in mental health in Canada: Child and youth mental health. Library of Parliament

56. Government of Canada Statistics Canada (2020) The Daily Vast majority of students attended public schools prior to the pandemic. https://www150.statcan.gc.ca/n1/daily-quotidien/201015/ dq201015a-eng.htm. Accessed 4 Oct 2021

57. Janus M, Walsh C, Duku E (2005) Early Development Instrument: Factor structure. Offord Centre for Child Studies, McMaster University, Hamilton, ON, Sub-domains and Multiple Challenge Index

58. Brinkman S, Gregory T, Harris J, Hart B, Blackmore S, Janus M (2013) Associations between the Early Development Instrument at age 5, and reading and numeracy skills at ages 8, 10 and 12: a prospective linked data study. Child Ind Res 6:695-708. https:// doi.org/10.1007/s12187-013-9189-3

59. Guhn M, Gadermann AM, Almas A, Schonert-Reichl K, Hertzman C (2016) Associations of teacher-rated social, emotional, and cognitive development in kindergarten to self-reported wellbeing, peer relations, and academic test scores in middle childhood. Early Childhood Res Q 35:76-84. https://doi.org/10.1016/j.ecresq.2015. 12.027

60. Brinkman S, Sayers M, Goldfeld S, Kline J (2009) Population monitoring of language and cognitive development in Australia: the Australian Early Development Index. Int J Speech Lang Pathol 11:419-430. https://doi.org/10.1080/17549500903147552

61. Achenbach TM, Dumenci L, Rescorla LA (2003) DSM-oriented and empirically based approaches to constructing scales from the same item pools. J Clin Child Adolesc Psychol 32:328-340. https://doi.org/10.1207/S15374424JCCP3203_02

62. Goodman R (2001) Psychometric properties of the Strengths and Difficulties Questionnaire. J Am Acad Child Adolesc Psychiatry 40:1337-1345. https://doi.org/10.1097/00004583-20011 $1000-00015$

63. IBM Corp. (2017) IBM SPSS Statistics for Windows, Version 25.0. IBM Corp., Armonk, NY

64. Grenier S, Payette M-C, Gunther B, Askari S, Desjardins FF, Raymond B et al (2019) Association of age and gender with anxiety disorders in older adults: a systematic review and meta-analysis. Int J Geriatr Psychiatry 34:397-407. https://doi.org/10.1002/gps. 5035

65. Lewinsohn PM, Gotlib IH, Lewinsohn M, Seeley JR, Allen NB (1998) Gender differences in anxiety disorders and anxiety symptoms in adolescents. J Abnorm Psychol 107:109-117. https://doi. org/10.1037//0021-843x.107.1.109

66. McLean CP, Asnaani A, Litz BT, Hofmann SG (2011) Gender differences in anxiety disorders: prevalence, course of illness, comorbidity and burden of illness. J Psychiatr Res 45:1027-1035. https://doi.org/10.1016/j.jpsychires.2011.03.006

67. Essau CA, Lewinsohn PM, Lim JX, Ho MHR, Rohde P (2018) Incidence, recurrence and comorbidity of anxiety disorders in four major developmental stages. J Affect Disord 228:248-253. https:// doi.org/10.1016/j.jad.2017.12.014

68. Feehan M, Mcgee R, Williams SM (1993) Mental health disorders from age 15 to age 18 years. J Am Acad Child Adolesc Psychiatry 32:1118-1126. https://doi.org/10.1097/00004583-19931 1000-00003

69. Cohen P, Cohen J, Kasen S, Velez CN, Harmark C, Johnson J et al (1993) An epidemiological study of disorders in late childhood and adolescence-I. Age- and gender-specific prevalence. J Child Psychol Psychiatry 34:851-867. https://doi.org/10.1111/j. 1469-7610.1993.tb01094.x

70. Compton SN, Nelson AH, March JS (2000) Social phobia and separation anxiety symptoms in community and clinical samples of children and adolescents. J Am Acad Child Adolesc Psychiatry 39:1040-1046. https://doi.org/10.1097/00004583-20000 8000-00020
71. Gobrial E, Raghavan R (2012) Prevalence of anxiety disorder in children and young people with intellectual disabilities and autism. Adv Ment Health Intellect Disabil 6:130-140. https://doi. org/10.1108/20441281211227193

72. Green SA, Berkovits LD, Baker BL (2015) Symptoms and development of anxiety in children with or without intellectual disability. J Clin Child Adolesc Psychol 44:137-144. https://doi.org/10. 1080/15374416.2013.873979

73. Horwitz S, Kerker B, Owens P (2000) The health status and needs of individuals with mental retardation. Department of Epidemiology and Public Health, Yale University School of Medicine, New Haven, Connecticut

74. Whitaker S, Read S (2006) The prevalence of psychiatric disorders among people with intellectual disabilities: an analysis of the literature. J Appl Res Intellect Disabil 19:330-345. https://doi.org/ 10.1111/j.1468-3148.2006.00293.x

75. Zheng Y (2008) Anxiety and second/foreign language learning revisited. Canadian Journal for New Scholars in Education/ Revue canadienne des jeunes chercheures et chercheurs en éducation 1(1)

76. Deb S, Thomas M, Bright C (2001) Mental disorder in adults with intellectual disability. 1: prevalence of functional psychiatric illness among a community-based population aged between 16 and 64 years. J Intellect Disabil Res 45:495-505. https://doi.org/10. 1046/j.1365-2788.2001.00374.x

77. Gillott A, Furniss F, Walter A (2001) Anxiety in high-functioning children with autism. Autism 5:277-286. https://doi.org/10.1177/ 1362361301005003005

78. Lau BY, Leong R, Uljarevic M, Lerh JW, Rodgers J, Hollocks MJ et al (2020) Anxiety in young people with autism spectrum disorder: common and autism-related anxiety experiences and their associations with individual characteristics. Autism 24:11111126. https://doi.org/10.1177/1362361319886246

79. Baurain C, Nader-Grosbois N (2013) Theory of mind, socioemotional problem-solving, socio-emotional regulation in children with intellectual disability and in typically developing children. J Autism Dev Disord 43:1080-1097. https://doi.org/10.1007/ s10803-012-1651-4

80. Conner CM, White SW, Scahill L, Mazefsky CA (2020) The role of emotion regulation and core autism symptoms in the experience of anxiety in autism. Autism 24:931-940

81. Mazefsky CA, Herrington J, Siegel M, Scarpa A, Maddox BB, Scahill L et al (2013) The role of emotion regulation in Autism Spectrum Disorder. J Am Acad Child Adolesc Psychiatry 52:679_ 688. https://doi.org/10.1016/j.jaac.2013.05.006

82. Horwitz EK, Horwitz MB, Cope J (1986) Foreign language classroom anxiety. Mod Lang J 70:125-132. https://doi.org/10.1111/j. 1540-4781.1986.tb05256.x

83. Price ML (1991) The subjective experience of foreign language anxiety: interview with highly anxious students. In: Horwitz EK, Young DJ (eds) Language anxiety: from theory and research to classroom implications. Prentice Hall, Englewood Cliffs, NJ, pp 101-108

84. Young DJ (1991) Creating a low-anxiety classroom environment: What does language anxiety research suggest? Mod Lang J 75:426-437. https://doi.org/10.1111/j.1540-4781.1991.tb05378.x

85. Young DJ (1994) New directions in language anxiety research. In: Klee CA (ed) Faces in a crowd: The individual learner in multisection courses. Boston, MA, pp 3-46

86. Government of Canada Statistics Canada (2018) The Daily Elementary-Secondary Education Survey for Canada, the provinces and territories, 2016/2017. https://www150.statcan.gc.ca/ n1/daily-quotidien/181102/dq181102c-eng.htm. Accessed 3 Mar 2021

87. Coplan R, Findlay LC, Schneider BH (2010) Where do anxious children "fit" best? Childcare and the emergence of anxiety in 
early childhood. Can J Behav Sci/Revue canadienne des sciences du comportement 42:185-193. https://doi.org/10.1037/a0019280

88. Chronis-Tuscano A, Danko CM, Rubin KH, Coplan RJ, Novick DR (2018) Future directions for research on early intervention for young children at risk for social anxiety. J Clin Child Adolesc Psychol 47:655-667. https://doi.org/10.1080/15374416.2018.14260 06

89. Rapee RM, Kennedy S, Ingram M, Edwards S, Sweeney L (2005) Prevention and early intervention of anxiety disorders in inhibited preschool children. J Consult Clin Psychol 73:488-497. https:// doi.org/10.1037/0022-006X.73.3.488
90. Chronis-Tuscano A, Rubin KH, O’Brien KA, Coplan RJ, Thomas SR, Dougherty LR et al (2015) Preliminary evaluation of a multimodal early intervention program for behaviorally inhibited preschoolers. J Consult Clin Psychol 83:534-540. https://doi.org/10. 1037/a0039043

Publisher's Note Springer Nature remains neutral with regard to jurisdictional claims in published maps and institutional affiliations. 